\title{
AC 2008-2296: IMPACT OF RAPID PROTOTYPING FACILITIES ON ENGINEERING STUDENT OUTCOMES
}

\section{James Helbling, Embry-Riddle Aeronautical University}

Currently an Associate Professor of Aerospace Engineering where he teaches structural analysis, computer aided conceptual design, and aircraft detail design courses. He has 21 years of industry experience with McDonnell Douglas (now Boeing) and Northrop Grumman Corporation where he specialized in structural fatigue loading and served as manager of F-5/T-38 Engineering.

\section{Lance Traub, Embry-Riddle Aeronautical University}

Currently an Associate Professor of Aerospace Engineering where he teaches experimental methods, wind tunnel testing and high speed aerodynamics. He has over 14 years of experience in applied research and teaching. Dr. Traub is the author of over 45 reviewed journal articles and 10 conference papers. 


\title{
IMPACT OF RAPID PROTOTYPING FACILITIES ON ENGINEERING STUDENT OUTCOMES
}

\begin{abstract}
Embry-Riddle Aeronautical University (ERAU) has formed a reputation for providing undergraduate students with a curriculum which has a strong emphasis on hands-on, application based learning. In an effort to improve this learning environment, the campus has recently added a Rapid Prototyping Laboratory which contains three 3-dimensional printers. The printers are used in courses throughout the aerospace engineering curriculum starting during the freshmen year and continuing through the senior year of study. Students get introduced to the rapid prototyping concept in their initial multi-disciplinary design course during their freshmen year, and then are given the opportunity to fabricate wind tunnel models during a sophomore year design course. Junior and senior level students make use of the 3-dimensional printers to facilitate verification of experimental concepts in laboratories or for creating physical models representative of their designs.
\end{abstract}

This paper discusses the impact the rapid prototyping facilities have had on student outcomes as defined for various laboratory and design based courses, and how these correspond to the outcomes defined by ABET. The process students follow to create the 3-dimensional models from files generated using computer aided design (CAD) software is explained. The impact on student learning in laboratory courses which make use of rapid prototyping is defined both qualitatively and quantitatively. A special emphasis is placed on the impact on student learning in the senior capstone courses, which involve the fabrication of models used to verify design assumptions made during preliminary design phases. These models allow for timely instruction in testing methods utilized in industry and graduate programs using more sophisticated models. Also discussed is the improved ability for faculty to perform undergraduate research and improve the learning environment outside of the traditional classroom setting. The paper concludes with a summary of the overall improvement in the undergraduate learning environment and proposed curriculum improvements which are directly tied to the rapid prototyping facility.

\section{Introduction}

The following sections provide insight into the improvement in ERAU student outcomes resulting from the addition of new rapid prototyping facilities. These outcomes are defined by the College of Engineering in accordance with ABET a-k criteria ${ }^{1}$. The particular outcome which is most directly impacted by the new facilities states: "All engineering students will be laboratory and computer proficient with modern equipment and current laboratory and computer methods." 2 The impact on student outcomes for individual courses will be discussed on a course-by-course basis.

The paper begins with an overview of the rapid prototyping facility, which provides the chronological sequence of events that led to the lab's current status and provides a description of the process used by students to create the rapid prototyped parts. The subsequent sections provide a course-by-course review recounting the impact of the new facility on the courses 
where it has had the most influence. The paper concludes with a summary of how the facility has impacted the students' ability to mesh theory, computation, and experimentation and a discussion of planned curriculum improvements now made possible with the addition of the new laboratory.

\section{RP Lab Overview}

The Rapid Prototyping Laboratory is a 238 square foot facility that contains two work stations that are connected to three 3D printers. The oldest of the three is a Zcorporation Zprinter310 plaster printer which was purchased in Fall 2005. The impetus for the purchase of this printer was to support a freshmen multidisciplinary design course which was being offered for the first time that semester. Two Stratasys Dimension SST printers which form parts made of ABS plastic were subsequently purchased during the Fall 2006 and Spring 2007 semesters. These printers are used for sophomore through senior level courses to create higher fidelity models with improved strength characteristics. Additional details regarding the use of these printers in individual courses and in undergraduate research are provided in the sections which follow. A photograph showing the three printers is provided in Figure 1, below.

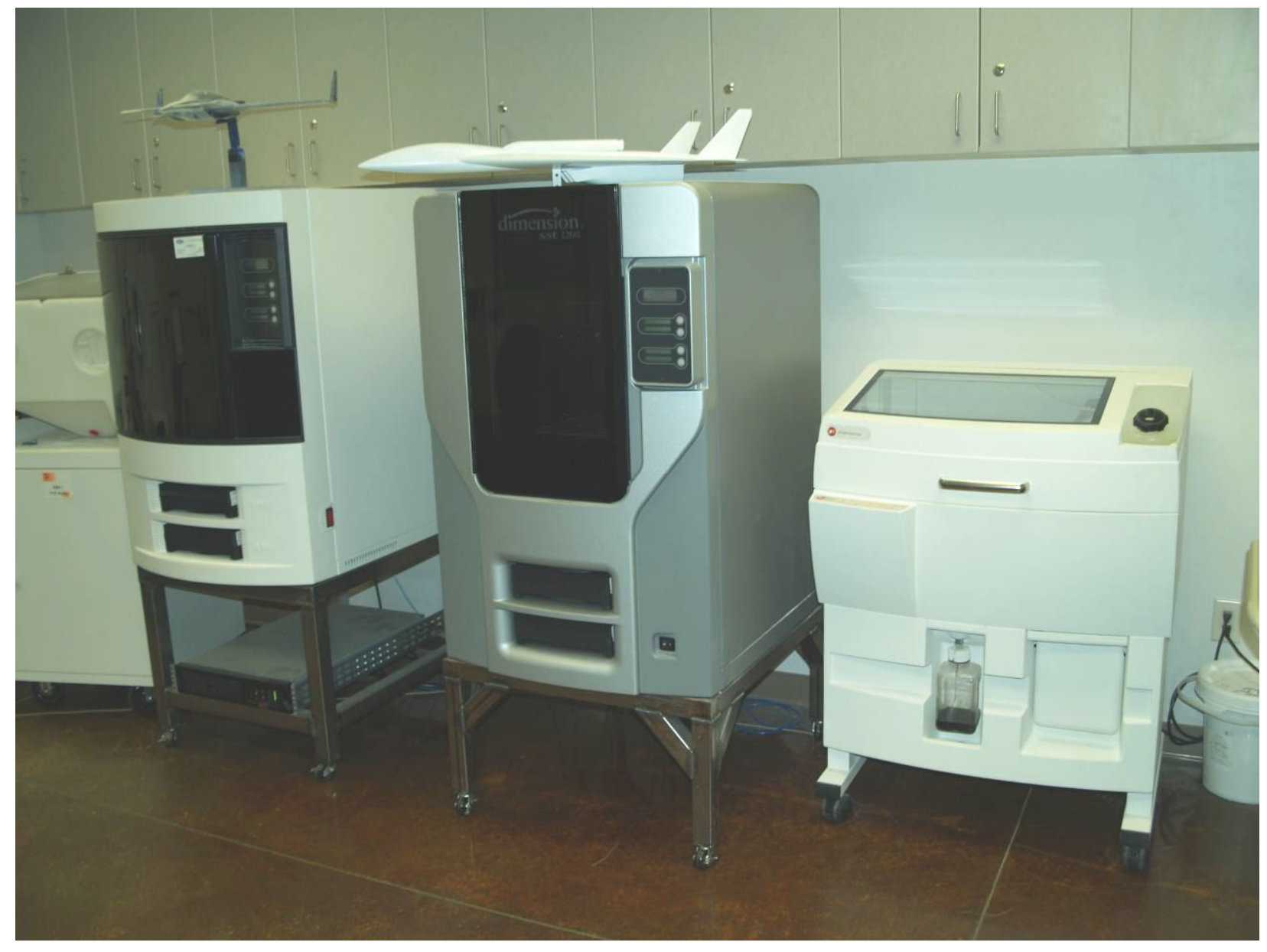

Figure 1: 3D Printers 
The Stratasys printers are shown on the left of the figure. The process used for creating parts in the 3D printers begins with the generation of solid CAD models using either CATIA or SolidWorks software. The CAD models are then converted to the printer language and imported. The Zcorporation Zprinter310 plaster printer creates parts from the bottom up by injecting a hardening agent onto a thin layer of powdered plaster which is pulled from a bin onto a build platform. The hardening agent is applied to the plaster layer using an inkjet nozzle in a pattern specified by the CAD file. After the cross section is completed for each layer, the build platform drops down by a small increment allowing the next layer of plaster to be pulled onto the platform, and the process repeats the part is completed.

The Stratasys Dimension SST printers also build parts from the bottom up, but use thin plastic thread which is melted onto a build platform in the pattern defined by the imported CAD file. Two types of plastic are used: a white ABS plastic which forms the completed part and a soluble black plastic which is used as necessary to support the part as it is being built. The soluble plastic is broken away or melted using a heated lye bath once the build process is complete. A view of the build area of one of these printers showing the build platform is shown in Figure 2, below.

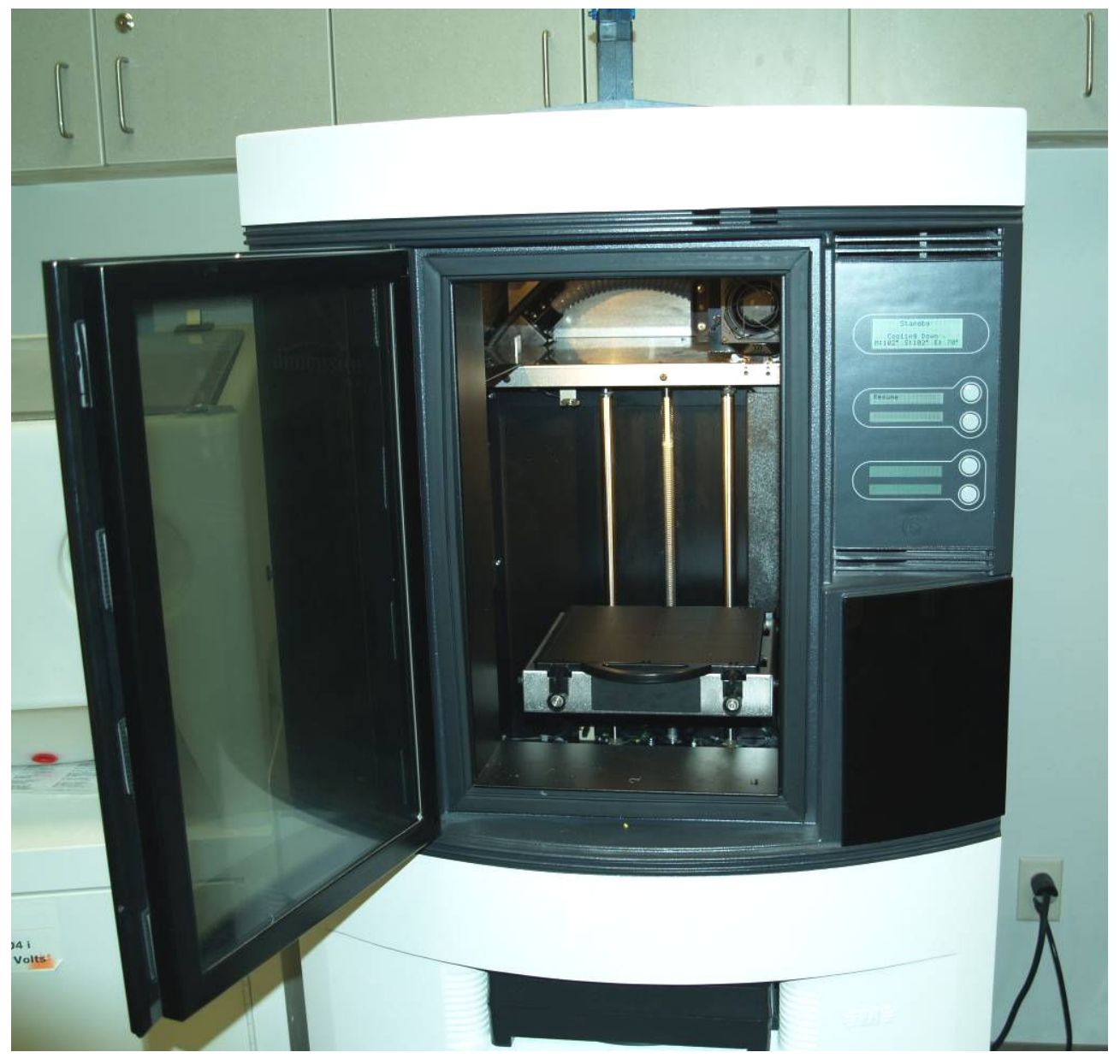

Figure 2: Build Area for ABS Plastic Printer 
The size of the build area for the printer shown is 8-in. by 8-in. by 10-in. This is the smaller of the two Stratasys printers, with the larger having a build area of 10-in. by 10-in. by 12-in.

A policy has been established for use of the Rapid Prototyping Lab by students to allow fair and equitable access to the printers. The build times for parts can be rather lengthy, especially for those for which aerodynamic shaping is critical. Therefore, all parts to be fabricated must be approved by a faculty member who is placed in charge of the lab and who ensures that the parts have some stated academic purpose. The CAD files are then brought to one of two lab technicians, who evaluate the parts in terms of fidelity, projected build time, and cost. Build jobs (which typically consist of several parts which make up an assembly) are limited to a 48 hour build time and $\$ 500$ cost. The senior capstone design courses are given priority, with all other courses queued on a first come first served basis. This system has proved effective in allowing adequate access to the printers, but students still must account for the queue and lengthy build times in their project schedules, which provides a valuable lesson in project management.

The following sections provide additional insight into the impact of the rapid prototyping facility on the courses which are most impacted by them. The sections are presented in order of increasing complexity starting with the freshmen design experience and ending with the senior capstone design course.

\section{Introduction to Engineering}

At ERAU, first-year engineering students are required to take an Introduction to Engineering course in their first semester. This is a multi-disciplinary design course where student teams initially use the Lego Mindstorms system to design, build, and program a robot for a specific competitive mission. During the later half of the semester, student teams incorporate the Mindstorms controllers and sensors into a lighter-than-air vehicle design which is entered into a second competition. This second project allows for the introduction of simple rapid prototyped parts formed from SolidWorks solid models generated by the students for the purpose of housing the Mindstorms components.

The first time this course was offered, these components were fabricated using the Zcorporation plaster printer discussed previously. However, it was quickly discovered that the plaster parts were very heavy and brittle; two qualities not conducive to lighter-than-air vehicle designs. Therefore, beginning with the Fall 2006 semester when the first ABS plastic printer was purchased, teams began incorporating the stronger and lighter plastic parts into their designs. The primary problem with this was the time required to build their models, which were not ready for printing until near the end of the semester when time is of a premium. For this reason, only a small percentage of the 50+ student teams per semester have been able to use the printed parts for their vehicles, with the remainder resorting to the use of Legos.

Nevertheless, all 200+ students enrolled in the course each semester are exposed to the development of CAD files for the purpose of generating rapid prototyped parts. The ABET student outcomes which are most readily impacted by this experience are Outcomes 6 and $8 .^{2}$ These outcomes state that students must show an aptitude for design (Outcome 6) and proficiency in the use of modern laboratory equipment (Outcome 8). Although the freshmen 
student knowledge base is minimal during their first semester, their exposure to the rapid prototyping methods as a means for creating design components prepares them for the more advanced uses to which they will be exposed in subsequent courses.

\section{Computer Aided Conceptual Design}

As Aerospace Engineering students progress into their sophomore year, they are given the opportunity to perform more advanced design trade studies in the Computer Aided Conceptual Design of Aerospace Systems course. This course was added to the ERAU curriculum in Fall 2006 to allow sophomore students to conceptualize aircraft and spacecraft designs using basic aerodynamic and space mechanics principles. To support the aircraft designs, student teams create wind tunnel models representative of their designs using the ABS plastic printers. These models are first generated as CATIA solid model assemblies and are then fabricated, assembled, and mounted in a low speed wind tunnel for the purpose of performing flow visualization testing. A sample of the models created by students enrolled in this class is shown in Figures 3, below.

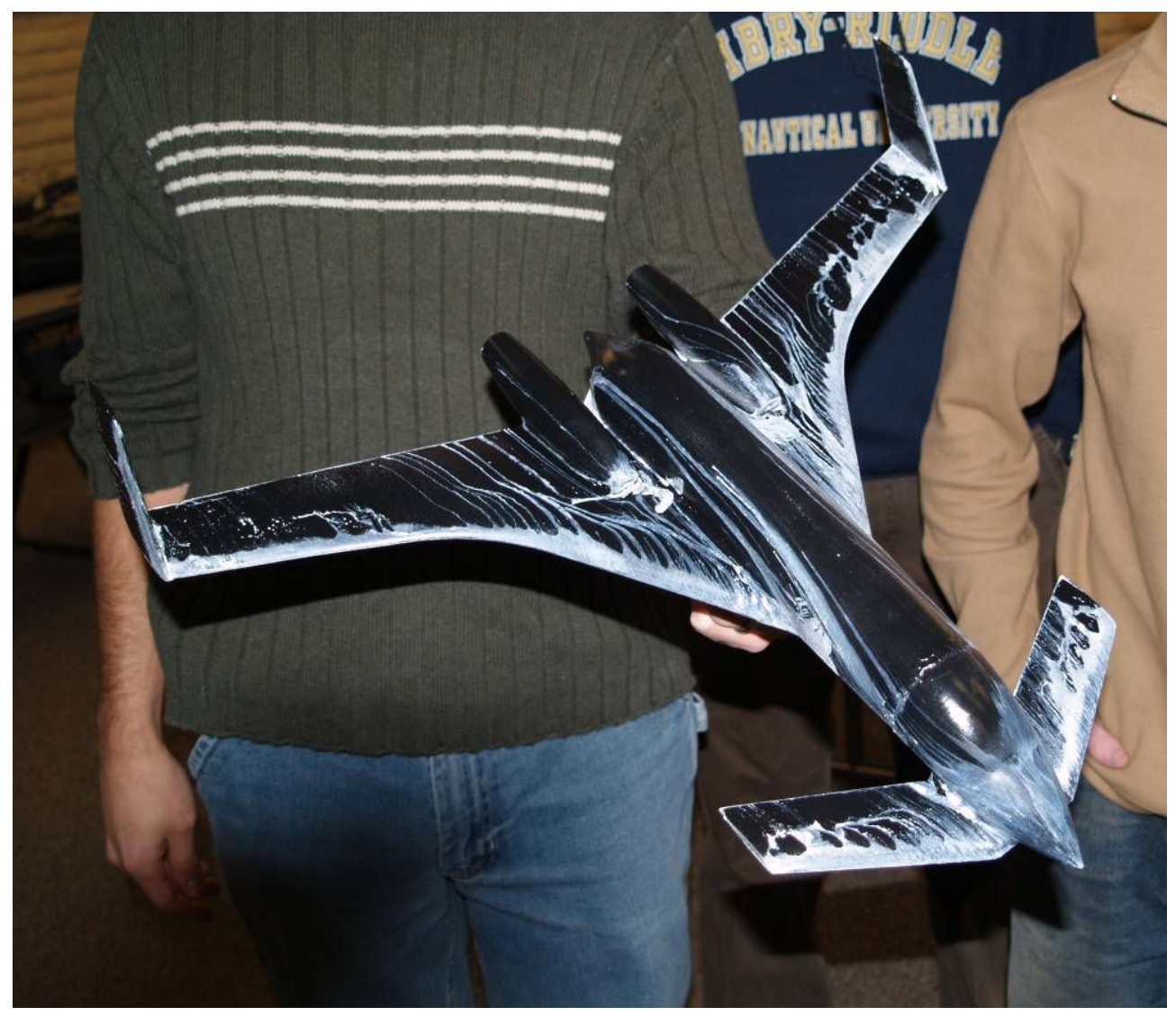

Figure 3: Sophomore Design Wind Tunnel Model

The titanium dioxide flow visualization paint is evident on this particular model, which provided evidence of the downwash effect produced by the canard on the right main wing of the model at high angles of attack. This effect is not evident on the left side of the model which was tested at a lower angle of attack, which validated the redesign proposed by the students. 
The students in this course use the rapid prototyping system to learn about the fabrication of aerodynamically shaped parts, and use these parts to validate their design assumptions. Perhaps more importantly, they learn about the assembly of these parts accounting for the tolerances required to form a model representative of an actual aircraft. In order to create a model suitable for wind tunnel testing, all mated surfaces must be joined so that gaps and surface imperfections are minimized which would distort the results of their testing. By performing these tasks in conjunction with their analytical trade studies, Outcomes 6 and $8^{2}$ as described in the previous section are clearly enhanced. In doing so, this course forms another stepping stone on the path to the capstone design experience.

\section{Experimental Aerodynamics}

Experimental Aerodynamics is typically a junior level laboratory consisting of a 1 hour class period supporting a 2 hour 40 minute laboratory. The students perform six pre-designed laboratories which elucidate various aerodynamic concepts. Of these laboratories, half use wind tunnel models that have been fabricated using rapid prototyping technology. Rapid prototyping the components has allowed for the design of fairly complicated models examining concepts such as leading and trailing edge flaps. Models can be manufactured quickly and inexpensively using the ABS plastic printers. This capability also promotes frequent changing of experiments, keeping them interesting and relevant for both the instructor and student alike.

An additional component of the aerodynamics laboratory is independent study by the laboratory teams. Students are encouraged to conceive and implement an experiment to test a concept they find interesting. The process is initiated with a literature search. The proposed project is discussed with the teacher and its feasibility ascertained. The students then design a wind tunnel model to implement the experiment. Models are designed using CATIA and are then rapid prototyped and assembled. There are significant advantages to rapid prototyping the models. The complexity of conceived experiments is no longer hindered by manufacturing difficulty (e.g. incorporating different airfoil sections and twist in a wing). Machine shop manufacturing resources (such as milling and turning) are not required, reducing costs and time to manufacture. Unlike more traditional model fabrication methods, students see the manufacturing component as an enjoyable part of the laboratory process where their CATIA skills are used, and they do not have to wait excessive amounts of time for their parts to be manufactured from a significantly backed up machine shop. Time to re-manufacture parts that were perhaps incorrectly designed is also reduced. The laboratory curriculum ensures significant exposure to desired ABET outcomes, such as laboratory and computer proficiency (Outcome 8) ${ }^{2}$. Additionally, wind tunnel model conception and manufacture improves student design skills though real world application (Outcome 6) ${ }^{2}$. A typical model designed by students is shown in Figure 4 on the next page. 


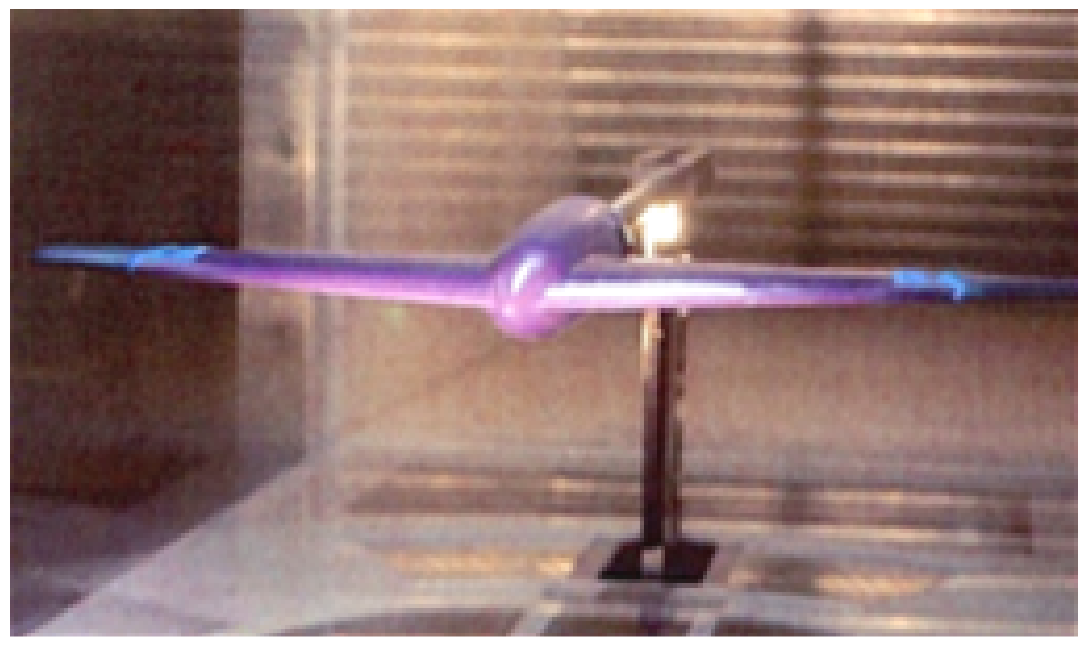

Figure 4: Rapid Prototyped Model Designed to Explore Wing Tip Sails

The wing sails installed at the wing tips of this model are shown in blue. The sails are being used to investigate a potential reduction in wing tip vortices and resulting downwash.

Fundamental manufacturing skills are not lost as a part of this process as students still need to assemble the models from the separate rapid prototyped parts, as few models, if any, consist of a single element. Consequently, models are seldom designed that could not be manufactured using more traditional methods (if, perhaps with more effort).

\section{Aircraft Detail Design}

The ERAU Aircraft Detail Design course is the second of a two-part capstone sequence during which design teams perform detail design on an aircraft conceptualized in the Aircraft Preliminary Design course. The course requirements include the design, fabrication, and testing of both wind tunnel and structural models representative of a chosen aircraft component, or, alternatively, the design, build, and fly of a scaled down aircraft model. The wind tunnel testing of this effort requires students to fabricate high fidelity models which are utilized to verify the aerodynamic and stability characteristics of their designs. In cases where design, build, fly is the focus, two competing teams fabricate their wind tunnel models for the purpose of defining the design which provides the most promise for successfully completing a flight test program. In both cases, the rapid prototyping lab is used extensively in creating the parts which form the wind tunnel model assembly.

Due to the heavy workload in this course, students enrolled in this class prior to the acquisition of the first ABS plastic printer were force to concentrate on creating a wind tunnel model representative of only a single aircraft component which would typically be formed out of wood. While the results from this testing were useful, they did not account for the interaction of the individual component with its adjoining members. Thus, the introduction of rapid prototyping allowed for a more complete evaluation of each teams design. Examples of models created to support both the individual component structural design and the design, build, fly competition are shown in Figures 5 and 6 on the next page. 


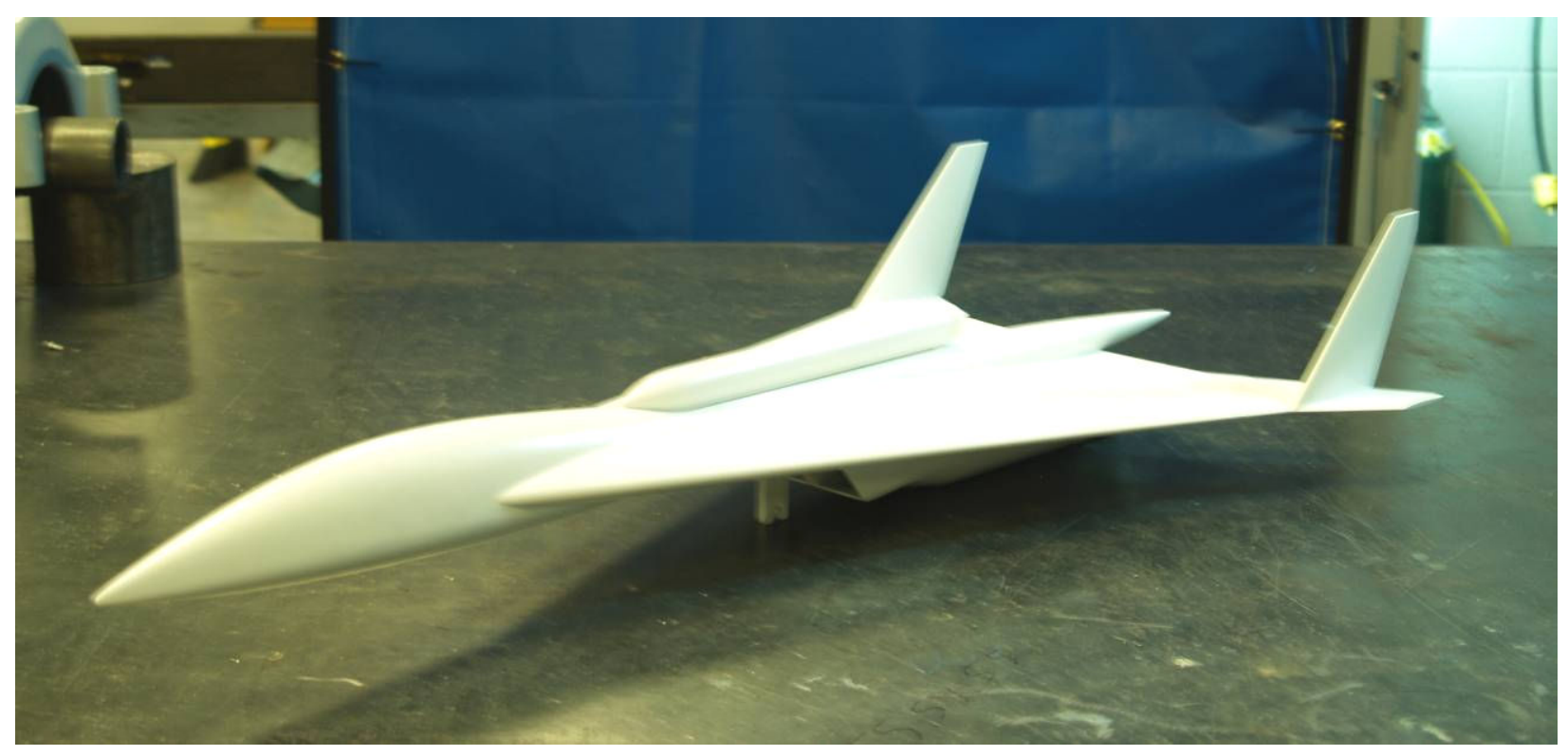

Figure 5: Wind Tunnel Model in Support of Wing Structural Design

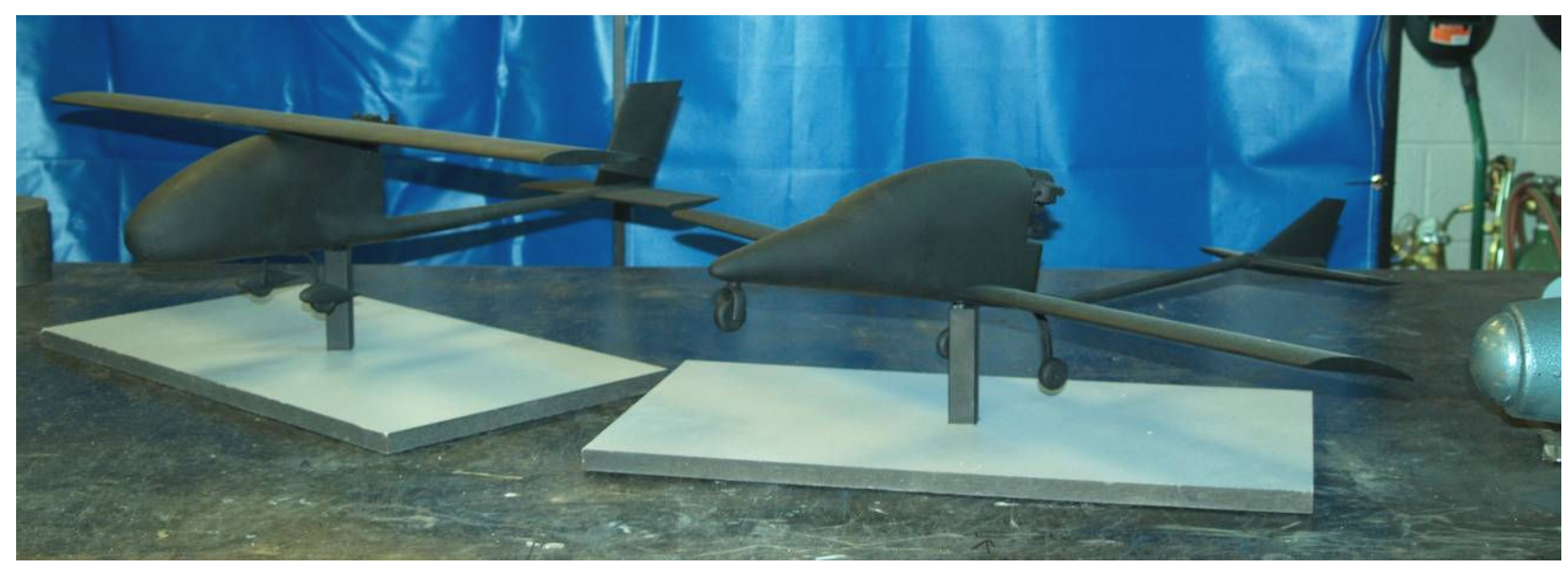

Figure 6: Two Wind Tunnel Models in Support of Design, Build, Fly Competition

The models shown in the preceding figures were formed using ABS plastic parts which were assembled using steel plates or rods and epoxy, and then sanded and painted to complete the process. Using this method allows teams more time to concentrate on other aspects of their design and still create aircraft models of high fidelity for use in collecting the aerodynamic data necessary to verify their design assumptions.

The ABET student outcomes which are most readily impacted by the rapid prototyping facilities for this class are Outcomes 6,7, and 8. ${ }^{2}$ Outcomes 6 and 8 have been previously defined, and Outcome 7 states that students must demonstrate design competence through a capstone experience. The improved facilities allow students to work in a modern environment which is similar to that which would be found in industry. This timely instruction for graduating seniors 
is invaluable in allowing them to complete their capstone projects using methods that will translate easily to those used in industry or graduate schools.

\section{Undergraduate Research}

A focused undergraduate research experience is encouraged at ERAU. Students are commonly funded though either external or internal grants. Students work closely with faculty to explore a topic of interest. In a recent example the student and faculty member explored aerodynamics of a selected airfoil at low speed. A model was designed that contained close to a 100 pressure taps, even though the model chord was only 4 inches long. The model was designed by the student using CATIA and rapid prototyped. Manufacture of such a wing otherwise would have been extremely laborious and time consuming. Computational fluid dynamics (CFD) comparisons with pressures measured over the wing showed close accord. Thus, not only are rapid prototyped parts time saving, but it has been shown that they can possess sufficient fidelity for research.

In another research program, an active flow control system was implemented. The system consisted of a vortex generator that was oscillated vertically. All components of the system were designed by the students involved and assembled. An image of the system is shown in Figure 7.

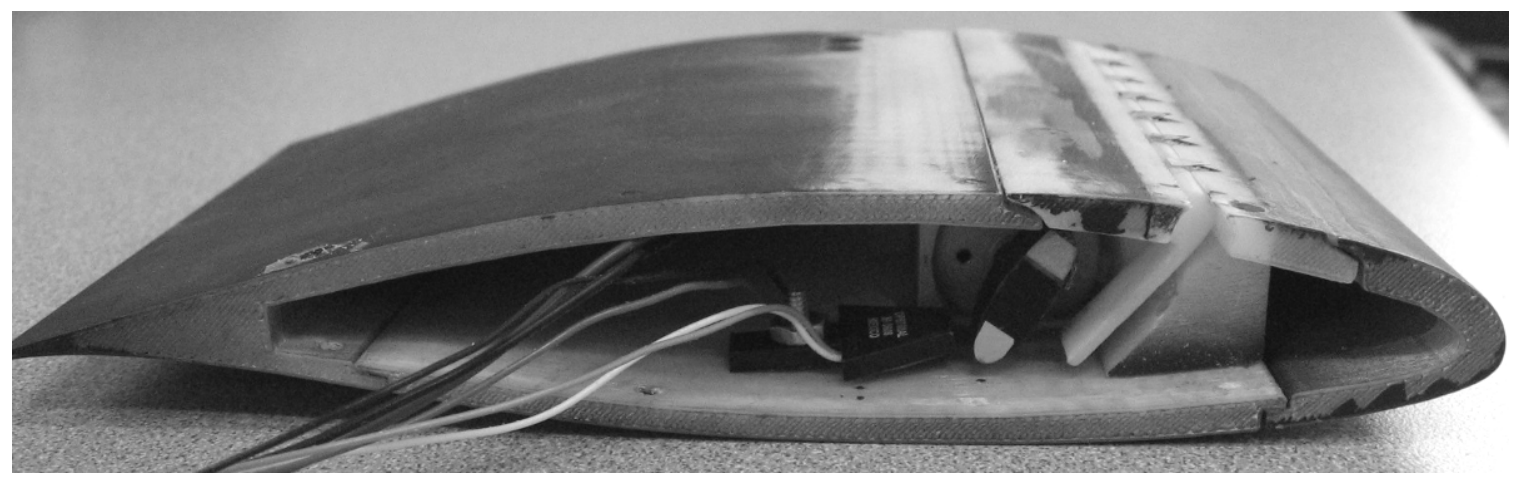

Figure 1 Rapid Prototyped Oscillatory Vortex Generator Model

As may be inferred, the design of a system such as that shown in the figure would have been challenging if conventional methods of manufacturing had been used. Not only does the use of rapid prototyping technology greatly improve the technical scope of what students can explore, but additionally, students are exposed to a learning experience usually only seen in graduate school. Rapid prototype technology has really allowed students to explore creative engineering solutions to problems less hindered by manufacturing constraints.

\section{Conclusion}

The previous sections have described several examples of how the new rapid prototyping facility has enhanced the ability of ERAU instructors to better meet student outcomes as defined by ABET. Of particular emphasis is the capability instructors now possess to mesh theory, computation, and experimentation into their instructional methods. Student feedback has been overwhelmingly positive regarding the curriculum enhancements which have resulted from the increased capability the new facilities bring. The improvement in all levels of instruction, from 
the freshman year through the senior capstone courses, has been notable. The AE faculty also have a high level of confidence that these enhancements will allow our department to further demonstrate ABET compliance during their scheduled 2010 visit.

Several course improvements are planned prior to 2010 which will be geared toward making better use of rapid prototyping equipment and utilizing additional equipment which is planned for procurement within the next few years. One example of this is the fabrication of space systems based components which may be used by students enrolled in the spacecraft capstone courses to evaluate the fit and function of close tolerance assemblies. New research opportunities may also arise due to the ability of students to fabricate aerodynamic components which may be used to evaluate state-of-the-art concepts. Additional curriculum improvements will be achieved once the faculty gain more experience in using the facility and more fully understand the capability of the equipment. In the meantime, the improvement in the undergraduate learning environment afforded by the Rapid Prototyping Laboratory continues to better prepare our students for the next phase of their academic or professional careers, thereby adding to ERAU's reputation for producing quality engineers who understand the relationship between theory and application.

\section{References}

${ }^{1}$ Criteria for Accrediting Engineering Programs Effective for Evaluations during the 2003 - 2004 Accreditation Cycle, Engineering Accreditation Commission, November 2002

${ }^{2}$ ABET Self-Study Report for the program in Aerospace Engineering, Embry-Riddle Aeronautical University, submitted to the Engineering Accreditation Commission, June 2004 